\title{
Tooth profile analysis of the vertical bearing capacity of the pile
}

\author{
Xue-feng Guo* \\ NO.78-2 zhong-xing west road Baicheng city of Jilin province, China (Baicheng Normal \\ College ) \\ 282534927@qq.com
}

\begin{abstract}
Keywords: pile foundation, sand lining, the tooth shape pile, the vertical bearing capacity Abstract: The foundation-structure of the building is an important research direction in the field of the geotechnical engineering. The pile foundation is the key research direction in the field of basic research, the pile foundation with its powerful bearing capacity is widely applied in engineering areas . however, improving the bearing capacity of the foundation is one problem we are facing. Usually, we are always considering the transfer efficiency between building foundatio $n$ and foundation load. In this paper, the tooth profile pile vertical bearing capacity is analyzed through flac $3 \mathrm{~d}$ analysis software, and through several experimental results prove the reliability of the results .
\end{abstract}

\section{Introduction}

The development of the profiled pile is not only reflected in the number, but also the structure and construction have some innovations. Due to the diversity of pile foundation in the form, the alienation can be from a different point of view, the alienation piles come from horizontal section and longitudinal cross section. The shape piles can be divided into constant cross-section piles and variable cross-section piles. No matter which angle it is, the objective is to distinguish the alienation characteristics from others

Clearly. The tooth shape pile is prefabricated structure of variable cross section, by tooth surface ,the tooth pile can be a whole structure with the foundation which the build is loading. The tooth pile gives full play to the body surface, to contact the soil and to increase the carrying capacity of pile body. Because of the existence of the tooth pile, the lateral force is not only as friction. This paper will simulate tooth pile under vertical load by software, observing the vertical displace at the top of the single pile, and comparing the experimental results through field experiment. Software simulate tooth pile and smooth pile bear vertical load, and contrasting experiment numerical curve [1-5]. 


\section{Load simulation software}

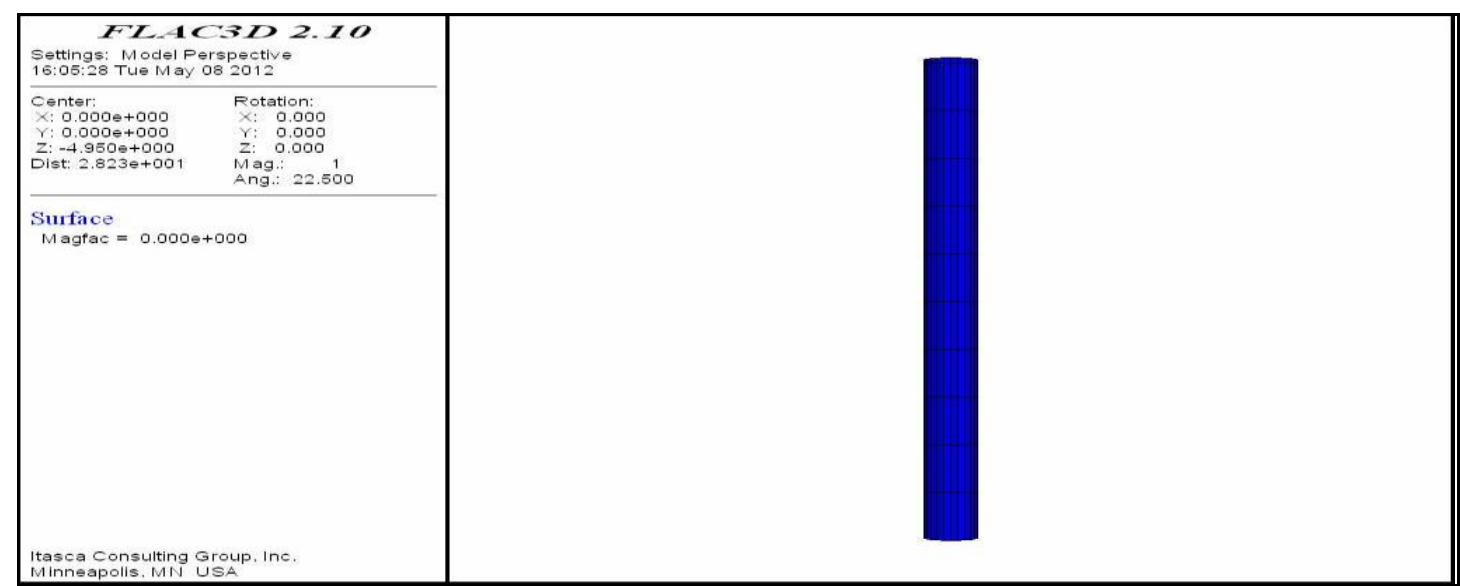

The Fig.1 The model graph of smooth pile in flac3d

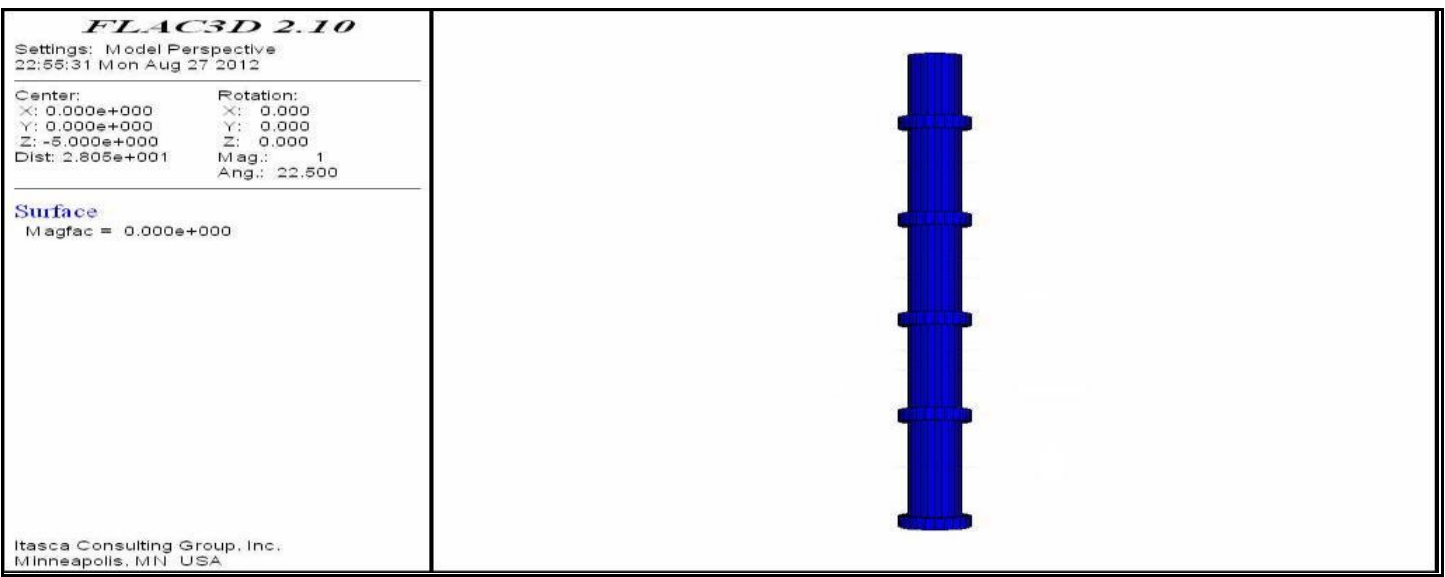

The Fig.2 The model graph of tooth shape pile in flac3d

As shown in figure 1, 2, structure model of smooth surface and tooth pile is set up, placed in homogeneous soil (the soil of simulation experiments: Moore - coulomb model, $\mathrm{C}=10, \Phi=340$; pile is the elastic model, 34 meters pile length, diameter 0.95 meters, rib diameter 1.05 meters) Loading tests are carried out, and record the change of pile top settlement.

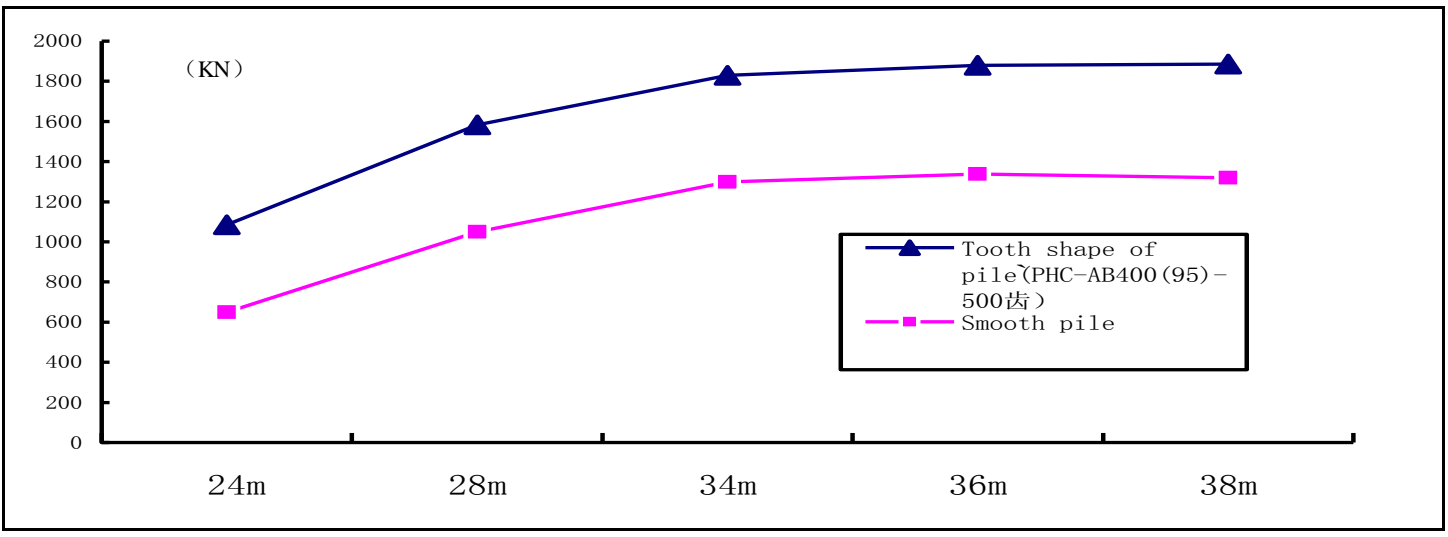

Fig. 3 the bearing capacity of the different length pile model in flac3d

Establishing smooth pile model as shown in figure 1 and the tooth shape of the model as shown in figure 2 by Flac3d software, through simulating the same stress environment, as 24 meters 28 meters、 34 meters、 36 meters、 38 meters tooth pile and smooth surface load eigenvalue. The 
analysis results of load eigenvalue is from tooth shape pile and smooth pile as shown in figure 3, 24 meters pile, its bearing capacity increased by $67.18 \%$; 28 meters pile, its bearing capacity increased by $50.86 \%$; Take $34 \mathrm{~m}$ pile and its bearing capacity increased by $40.90 \%$; Take 36 meters pile, the bearing capacity increased by $40.40 \%$; 38 meters pile, its bearing capacity increased by $42.88 \%$. The regular can be found of a single pile bearing capacity when pile length increase. The bearing capacity of characteristic value is not increased with the increase of pile length when pile length increase at a certain value. The ultimate bearing capacity depends on quantitative standard of the best length and the material strength soil and pile foundation. Comparing under the condition of different pile length, the characteristic value of the pile tooth vertical bearing capacity is much higher than that of smooth pile [6-16]。

\section{Field experiments}

In order to ensure the two piles in the same soil under vertical loads, the spacing of two pile is under strict control. When the soil structure is changed, It is observated that two pile is in the loading process and the influence to the soil. two piles is spaced as two meters, in the process of loading at the same time, the interference of another is avoided.
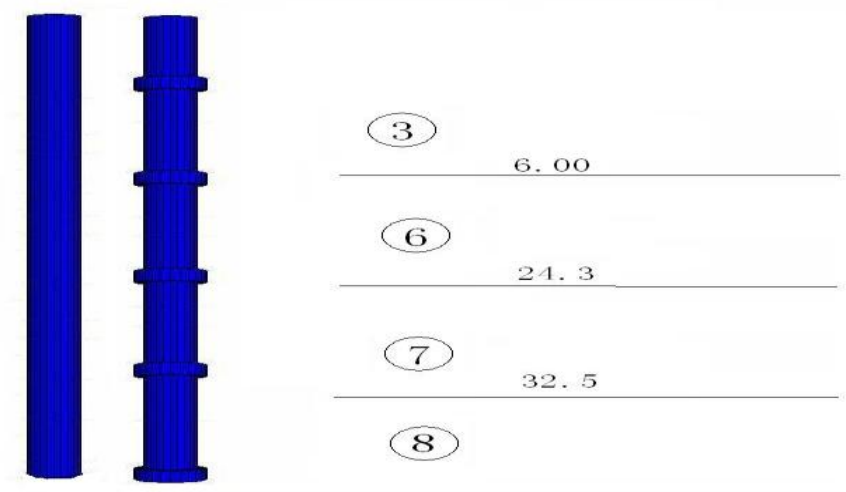

Fig.4

Within the scope of the two meters apart, it's carried on the test experiment, the soil structure is shown as figure 4. Two pile is loaded respectively, the results are shown in table 1 . In the process of loading, record the characteristic value of vertical bearing capacity and the corresponding settlement of two piles.

Soil information: (3)brown gray, bearl blue, soft - flow plastic is given as main , local plastic, saturated. (6)sand: brown gray, taupe, loose - intermediate dense , wet. (8) clay: dark gray, brown, gray, plastic is given as main, local hard plastic, saturated. Medium - high compressibility. 
Table.1 the contrast data of tooth pile and smooth pile

\begin{tabular}{|c|c|c|c|c|}
\hline \multirow{2}{*}{ Number of test pile } & $\begin{array}{c}\text { model } \\
\text { type }\end{array}$ & pile length & $\begin{array}{c}\text { Charact eristic value of } \\
\text { vertical bearing capacity of } \\
\text { single pile }\end{array}$ & Corresponding settlement \\
\hline $5 \#$ & PHC-AB400(95) -500 & $34 \mathrm{~m}$ & $2321 \mathrm{KN}$ & $5.40 \mathrm{~mm}$ \\
\hline $6 \#$ & PHC-AB400(95) & $34 \mathrm{~m}$ & $1906 \mathrm{KN}$ & $3.56 \mathrm{~mm}$ \\
\hline
\end{tabular}

Through comparison and analysis, it is easily found that the characteristic value of vertical bearing capacity of tooth shape pile significantly higher than the smooth characteristic value. Before reach characteristic value, the vertical force of the unit corresponding settlement: the tooth pile is $429.81 \mathrm{KN} / \mathrm{mm}$, smooth pile is $535.39 \mathrm{KN} / \mathrm{mm}$. Before reaches limit, the vertical force of the unit corresponding settlement: the tooth pile is $172.08 \mathrm{KN} / \mathrm{mm}$, the smooth pile is $144.06 \mathrm{KN} / \mathrm{mm}$.

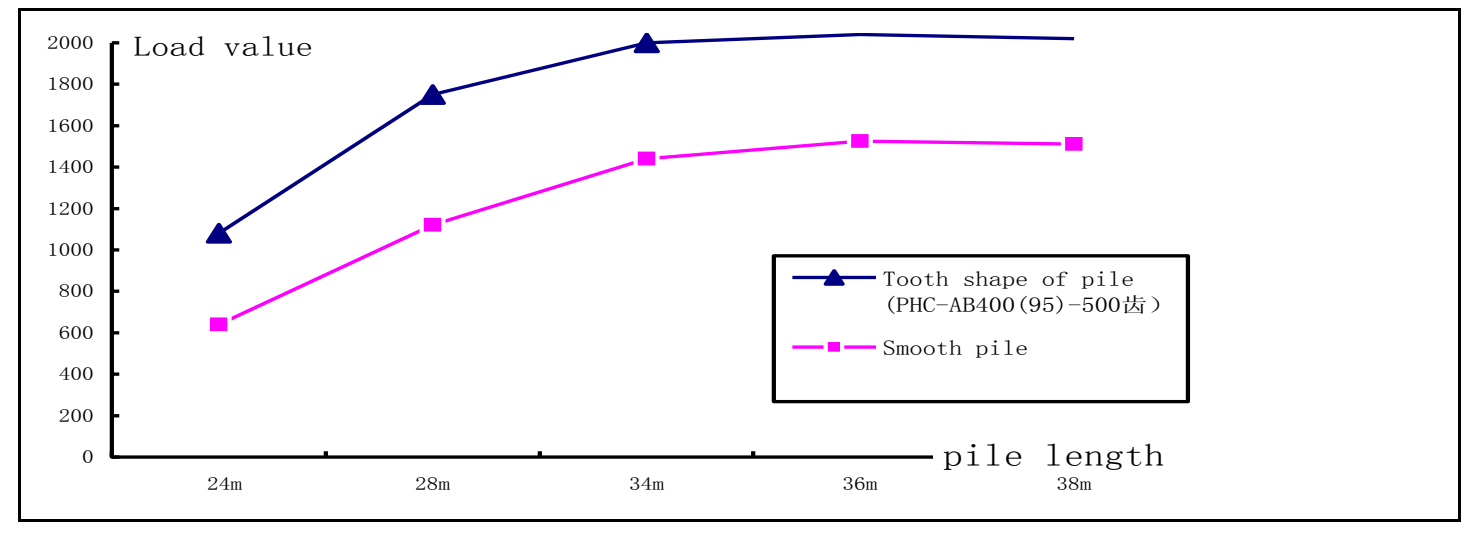

Fig.5 the bearing capacity of the different length pile

Through the site experiment of same geological conditions (sand lining information: $\mathrm{C}=0, \Phi=$ 340; soil layer information: $\mathrm{C}=10, \Phi=340$ ), result: $24 \mathrm{~m}, 28$ meters, 34 meters, 36 meters, 38 meters the bearing capacity characteristic value of tooth shape pile and smooth surface pile. the bearing capacity comparison results of tooth pile and smooth pile analysis is shown in figure 5.24 meters pile, the bearing capacity characteristic value increased by $68.75 \%$; 28 meters pile, its residual value increased by $56.25 \% ; 34$ meters pile and its residual value increased by $38.89 \% ; 36$ meters pile, the residual value increased by $33.68 \%$; 38 meters pile, its residual value increased by $33.67 \%$. The above results can be found such a feature, the bearing capacity of pile foundation in the process of pile length increases, residual value is not increased with increasing the length of the pile. in continue to load at a certain value, residual value have a little change. The standard of the best length need to consider the material strength of soil and pile foundation. Comparison of different pile length, the vertical residual of tooth pile is much higher than smooth pile.

\section{conclusion}

Through software simulation, comparison bearing capacity result of tooth pile with smooth surface in different length is higher than smooth pile by more than $30 \%$, in the scope of the carrying capacity. Through the appropriate modeling process, using the different loading conditions, the vertical load simulation experiment, finally it is drawn the load sharing ratio of a tooth pile 
components. Through simulation of tooth distance and size differences, it is observed clearly that the tooth pile has a great advantage in bearing capacity. If increasing the thickness of the tooth, as increasing the own weight of pile, and adverse bearing. Reducing the soil layer thickness between the two teeth at the same time, it is bad for the soil and pile embedded in solid. But because the soil layer between the two teeth increased, under the condition of the unit load, the compression quantity will increase, large settlement will be produced. Through the changes of pitch and tooth thickness, the influence analysis results of tooth pile experiment is simulated [14-21]. The tooth thickness of pile and the tooth distance of appropriate numerical on-site test is found out, theory proved by experimental data.

The following conclusions is from comprehensive of the above analysis:

(1) Pile length should be within a certain range, the bearing capacity can't improve by increasing pile length.

(2) The bearing capacity contrast graphic of the smooth and the tooth pile , the bearing capacity of tooth pile is higher than the bearing capacity of smooth pile as more $30 \%$ (same diameter).

(3) in addition, the teeth thickness of the bearing capacity produce a certain influence, pile will not damage with higher intensity, and considering the influence of tooth thickness on soil layer and the build-in relationship, the tooth thickness should not too big.

(4) the distance of tooths is have certain effect on the bearing capacity of pile, the tooth is in different position, also determines the role of each tooth is different. The maximum perturbation is from upper pile foundation, then the teeth department should move upwards. Moreover, different pile spacing also determines the thickness of the soil between piles, also affects soil compression between piles. The comprehensive analysis and the experimental conclusion is that tooth arrangement should not be too close or too far. The same number of teeth, the different distance determines different carrying capacity.

\section{reference}

[1] Chong Wang. Pipe pile 15 years development in China and future [A], precast concrete piles academic papers. 2004:8-10

[2] Tian-jian Lin. Modern theory of special-shaped columns and mechanical characteristics of [A], mechanics and practices. 1998 (10): 1-10

[3] Yuan-hai Jiang, wei from nine. Suggestions for the pipe pile industry present situation and the development of our country [B], concrete and cement products, 2007 (8) :31-32

[4] Yun Liang, Shi-fang Ren, Da-xin Geng. Large diameter variable cross-section pile vertical bearing capacity and settlement of algorithms [A]. Roadbed engineering, 2009 (6) : 50-51

[5] Zhuxiang Guo. Bamboo pile in building design institute of science of engineering, the application of shandong architectural engineering college journal [B], 20 o2 (6), about the (2) : 92-95

[6] Ke-ren Hu,yao-wu liu. Bamboo artificial dig-hole expanding bottom pile application [A]. Intelligence development of science and technology and economy, 2 ooo (4), 10 (4) : 72-74

[7] de-ling qian. Has high ability of squeezed branch pile in the engineering application research [J], journal of rock mechanics and engineering, 2003, 22 (4) : 678-682. 
[9] zhi-long Yang. Squeezed branch piles expansion single pile vertical bearing plant research [D], tianjin: tianjin university, 2000. Plant

[10] Xing-long wu. DX pile bearing force design analysis [J]. Journal of geotechnical engineering, 2000, $22(5): 581-585$.

[11] Jian-min Yu. Lin-hai Wan, Peng Guo, etc. Planted characteristics of squeezed branch piles expansion socket FLAC3D simulation [j]. Journal of north China institute of water conservancy and hydropower, 2006, 27 (4) : 78-81.

[12] Xiao-juan Gao, Yue-hui Li. Artificial dig-hole squeezed branch pile bearing properties experimental study [J]. Journal of geotechnical engineering, 2005, 12 (3) : 148-151.

[13] Feng Shi, Lai-bing Cai. Chun Liu. Artificial dig-hole expanding bottom pile bearing capacity test study [J]. Journal of engineering survey, 1999 (2) : 21 to 25.

[14] Chao-qun Hou. Artificial dig-hole plant expanding bottom pile vertical bearing force test research [D]. Xi 'an: xi 'an university, 2004

[15] Zhi-Fang Huo. Artificial dig-hole calculation of the force of expanding bottom pile vertical bearing plant [D]. Xi'an: chang 'an university degree thesis, 2002

[16] Gang Zheng, Chang-xiang Wang. Long cement mixing pile in soft soil load transfer mechanism study [J], journal of geotechnical engineering, 2002, 24 (6) : 675-679

[17] TAKASHI H, MADAN B K. Load tests on bored phe nodular piles in different ground conditions and the bearing capacity based on simple soil parameters Journal of Structural and Construction Engineering (Transactions of AIJ), 1995(1): 89-94.

[18] OGURA H, YAMAGATA K. A theoretical analysis on load-settlement behavior of nodular piles. [J]. Journal of Structural and Construction Engineering(Transactions of AIJ), 1988, 393: 152-164.

[19] OGURA H, YAMAGATA K, KISHIDA H. Study Oil bearing capacity of nodular cylinder pile by scaled model test. [J]. Journal of Structural and Construction Engineering(Transactions of AIJ), 1987, 374: 87-97.

[20] OGURA H, YAMAGATA K, OHSUGI F. Study on bearing capacity of nodular cylinder pile by full—scaled test of jacked piles. [J]. Journal of Structural and Construction Engineering (Transactions of AIJ), 1988, 386: 66-77.

[21]Lee C Y, Poulos H G, Hull T S. Effect of seafloor instability on offshore pile foundations[J].School of Civil and Mining Engineering.1991,729-737 